Revista de Antropología Social

ISSN: 1131-558X

http://dx.doi.org/10.5209/RASO.61861

\title{
¿Cuestión de sentido común?: deconstrucción cultural de las formas de criar a hijos e hijas
}

Gottlieb, Alma y DeLoache, Judy. 2017. A World of Babies: Imagined Childcare Guides for Eight Societies. Nueva York: Cambridge University Press.

¿Deben dormir los bebés solos en cunas? ¿O en la misma cama que sus padres y madres? ¿Cuál es la mejor manera de bañar a los recién nacidos? ¿Se debe hablar con los bebés, o es una pérdida de tiempo? Todo grupo social tiende a pensar que su manera de cuidar a niños y niñas es la forma obvia, natural y correcta de hacerlo. Una cuestión de sentido común. Sin embargo, Alma Gottlieb y Judy DeLoache nos presentan en su obra A World of Babies: Imagined Childcare Guides for Eight Societies que eso es algo muy relativo. A través de la descripción de distintas prácticas de crianza alrededor del mundo, las autoras reflejan que el «sentido común» es de todo menos común y que lo que en una cultura se puede considerar «natural», en otra se puede percibir como raro, exótico o incluso bárbaro (pp. 3-4).

Nos encontramos ante la segunda edición de $A$ World of Babies: Imagined Childcare Guides for Seven Societies (2000), una obra consolidada como clásico de la antropología en la que se presentan, a modo de manual, distintas formas de crianza (childcare) en siete culturas del mundo. Sin embargo, pudiendo pensar a priori que este volumen supusiera simplemente una actualización de las culturas que se trataban en el primer libro, Gottlieb y DeLoache nos sorprenden en esta segunda edición con la actualización de una de ellas más otras siete culturas nuevas. Una obra que seducirá tanto a futuros padres y madres como a profesionales, al tratarse de un tema que muestra de una forma anecdótica una realidad social siempre actual: la crianza de nuestros hijos e hijas. Y es que este interés por las estrategias del cuidado ha aumentado significativamente en los últimos años.

La obra comienza con una nota a los lectores explicando en qué consiste el libro. Cada capítulo supone un manual de crianza contextualizado en una cultura distinta. Todos los capítulos comienzan con una narración explicativa a través de las voces de distintos personajes que ubicarán al lector en el escenario cultural en cuestión. Estos personajes son referidos por las autoras como «cuasi-ficticios», ya que están fielmente basados en informantes protagonistas de las distintas investigaciones etnográficas que fundamentan esta obra. Así, con la intención de que estos conocimientos sean perpetuados en el tiempo, la misión de dichos personajes será la de enseñar e iniciar a la nueva generación de padres y madres en el mundo de la crianza.

En el capítulo 1, «Criando un mundo de bebés: crianza de hijos e hijas en el siglo XXI» (título original: Raising a world of babies: Parenting in the twenty-first century), Alma Gottlieb y Judy DeLoache introducen y contextualizan de manera global la situación actual sobre cuestiones como la mortalidad infantil, la nutrición, las enfermedades, la necesidad de supervisión y la enseñanza de técnicas de supervivencia, factores que influyen en la forma de criar de cada cultura. El capítulo lanza aque- 
llas preguntas que el libro pretende contestar: ¿qué impacto tiene la globalización en las vidas de padres, madres, hijos e hijas? ¿cómo se puede criar a niños y niñas en contextos violentos y bélicos? ¿cuáles son los desafíos que enfrentan aquellas familias musulmanas y judías en tiempo de islamofobia y antisemitismo general? ¿cómo gestionan padres, madres y abuelos disputas intergeneracionales sobre la crianza de sus hijos e hijas en contextos de rápido cambio social? ¿qué diferencias ocasionan aquellos gobiernos con políticas que apoyan sistemáticamente el bienestar familiar?

En el capítulo 2, «Nunca olvides de dónde vienes: criando bebés musulmanes de Guinea en Portugal» (título original: Never forget where you're from: Raising Guinean Muslim babies in Portugal), Michelle C. Johnson da a conocer las costumbres de crianza entre musulmanes de Guinea-Bissau que migraron en su día a Portugal. Tras una contextualización histórico-política de las relaciones entre ambos países, la autora presenta a Awa, una mujer que lleva viviendo 30 años en Portugal tras el estallido de la guerra civil en su país. Su marido decidió que ella como esposa principal y sus hijos debían trasladarse allí para comenzar una nueva vida. A partir de aquí, Awa narrará para aquellos nuevos padres y madres en situaciones similares a la suya, sus costumbres de crianza con la finalidad de que las tradiciones no se pierdan, ya que «tus hijos son, y siempre serán musulmanes guineanos, incluso aunque vivan en Portugal».

En el capítulo 3, «De la revolución cultural a la revolución del cuidado de niños y niñas: consejos contradictorios sobre crianza en la China contemporánea» (título original: From Cultural revolution to Childcare revolution: Conflicting advice on childrearing in contemporary China), Erin Raffety presenta al contexto chino como uno de los que ha sufrido mayores cambios familiares en el último siglo, hecho que ha provocado la aparición de diferencias sustanciales entre generaciones a la hora de criar. Así, Xu Yujin y su suegra, Liu Xiaoyuan, relatarán las dificultades cotidianas que suelen atravesar las familias chinas en un contexto en el que criar a un niño o a una niña siempre implica diferentes connotaciones además de una negociación entre psicología moderna, medicina, sabiduría tradicional, y otros muchos retos relacionados con la migración y el capitalismo global.

En el capítulo 4, «Un bebé para atarte al lugar: consejos de crianza de una madre palestina que vive bajo la ocupación» (título original: A baby to tie you to place: Childrearing advice from a Palestinian mother living under occupation), Bree Akesson comienza describiendo la historia de Palestina enmarcada en casi un siglo de continuo conflicto palestino-israelí. Desde un lugar donde la familia extensa es muy importante, los acuerdos recientes con Israel están desafiando la resistencia de estos lazos. En este caso, una madre palestina musulmana y profesora en una universidad de Palestina relata, orgullosa de quién es, su propia experiencia alrededor de las prácticas del embarazo, parto y crianza.

En el capítulo 5, «Crianza de niños y niñas en el nuevo país: consejos para madres inmigrantes en Israel» (título original: Childrearing in the new country: Advice for immigrant mothers in Israel), Deborah Golden retrata la sociedad israelí definiéndola como una sociedad compleja influida principalmente por dos factores determinantes: las guerras y las oleadas de inmigración. El manual es narrado por Esther, madre y experimentada profesora de preescolar al norte de Israel. A ella acuden muchas madres preguntando por sus hijos e hijas, tanto en cuestiones escolares como en cuestiones de crianza. Esther relatará las prácticas durante el parto, el cuidado del recién nacido o nacida, el ritual de circuncisión y la importancia de la familia en un contexto cambiante e inestable. 
En el capítulo 6, «Traer a tu hijo a esta vida de tiempos difíciles: Un camino Beng para el cuidado infantil en la Costa de Marfil posterior a la Guerra Civil» (título original: Luring your child into this life of troubled times: A Beng path for infant care in Post-Civil War Côte d'Ivoire), Alma Gottlieb presenta al grupo étnico Beng, uno de los más pequeños y menos conocidos del África Occidental. La economía de sus habitantes se sustenta en la agricultura, la caza y la recolección. A través de las voces de una abuela y un adivino Beng, se transmitirán las prácticas de crianza ancestral; entre ellas, se sugerirán remedios tradicionales para quedarse embarazada, el parto en los hogares, consejos y razones para prevenir un parto complicado, la importancia del nombre del bebé, métodos para su protección y curación de enfermedades, consejos prácticos durante sus primeros años de vida y qué hacer si este acaba muriendo.

En el capítulo 7, «De Mogadiscio a Minneapolis: criando a niños y niñas somalíes en una Era de Desplazamiento» (título original: From Mogadishu to Minneapolis: Raising Somali children in an Age of Displacement), Sirad Shirdon describe los hechos históricos que dan forma a la realidad somalí en EEUU, concentrada mayoritariamente en Minnesota. En un contexto de importante racismo y sentimiento antiinmigrante, Halima, una joven somalí que migró a EEUU a los 10 años, narra con tono nostálgico los tiempos pasados en Somalia y el proceso de integración vivido. Ella nos aconsejará cómo criar a descendientes somalís en EEUU reflejando diferencias culturales, la tradición somalí durante el embarazo, la «prisa» por un parto que acaba normalmente en cesárea y que es experimentada por las mujeres somalís en los hospitales americanos, los cuidados durante el puerperio, el proceso de la elección del nombre al recién nacido y las diferencias a la hora de criar a un niño o a una niña.

En el capítulo 8, «¿Quechua o español? ¿Escuela agrícola? Nuevos caminos para niños y niñas andinas en la postguerra civil de Perú» (título original: Quechua or Spanish? Farm school? New paths for Andean children in Post-Civil War Peru), Kate Feinberg Robins comienza por contextualizar la realidad peruana tras el conflicto interno armado que tuvo lugar entre los años ochenta y noventa. Así, desde la experiencia de una madre y su hija, se reflejan las fuertes rupturas culturales, lingüísticas y políticas que este precedente marcó en la sociedad peruana. Así, para no olvidar sus tradiciones y seguir recordando quiénes son y de dónde vienen, madre e hija dejarán por escrito muchas de sus costumbres durante la crianza, las diferencias entre el parto en casa y el hospitalizado y la importancia de padrinos y madrinas.

En el capítulo 9, «'Los niños iguales juegan mejor': criando a niños y niñas independientes en un Estado de Bienestar nórdico» (título original: «Equal children play best»: Raising independent children in a Nordic Welfare State), Mariah G. Schug da a conocer una de las regiones europeas más remotas de Dinamarca, las Islas Feroe, un país autónomo dentro del reino danés. En este caso, una mujer feroesa relata su trayectoria personal hasta convertirse en enfermera de maternidad, quien, como tal, entre otras funciones, visita regularmente a aquellas mujeres recién paridas y a sus bebés, y enseña estrategias de crianza tanto a padres como a madres. Esta mujer hará hincapié en la importancia de un compromiso mutuo en la pareja-crucial para una buena crianza-, proporcionará recomendaciones sobre cuidados durante el embarazo, y explicará la preferencia de muchas mujeres por querer experimentar el dolor del parto. También tratará otros temas a tener en cuenta, entre ellos que el nombre del recién nacido deberá constar entre los 500 nombres que el gobierno feroés dispone y que la importancia del cristianismo para las buenas relaciones comunitarias resulta clave en esta isla. 
El libro concluye con un apartado reservado a las autoras participantes en el libro. Aquí, estas compartirán comentarios sobre sus trabajos de campo y dirigirán sus agradecimientos a aquellas personas que les ayudaron a realizarlo. Además, en este cierre la obra proporciona una mirada general sobre los desafíos globales que supone la crianza en el siglo XXI. Celebrando y mostrando la diversidad de estas prácticas alrededor del mundo, la obra quiere remarcar la importancia de «ampliar horizontes», abrir las perspectivas individuales sobre la forma de criar, ya que en ocasiones las tradiciones pueden suponer un reto familiar y social en caso de que se decidiese «salirse de la norma», de manera que este libro puede ayudar a la reflexión sobre por qué actuamos de forma tan arraigada e incuestionada en determinadas ocasiones.

Así, si bien esta conciencia de la diversidad humana no pretende traer consigo la aplicabilidad de otras tradiciones, sí pretende promover una actitud más crítica hacia aquellas prácticas que decidimos adoptar o no para criar a nuestros hijos e hijas. Sin duda, A World of Babies: Imagined Childcare Guides for Eight Societies consigue a través de una narración cercana, fresca y creativa no solo ampliar las miras culturales de sus lectores y lectoras, sino también mostrar de una forma ingeniosa y original los resultados de rigurosos estudios antropológicos.

Alicia Paramita Rebuelta Cho Universidad Autónoma de Barcelona aliciaparamita.rebuelta@uab.cat 